\title{
Recruiting to Geosciences through Campus Partnerships
}

Cinzia Cervato, Dept. of Geological \& Atmospheric Sciences, Iowa State University, Ames, Iowa 50011, USA

\section{INTRODUCTION}

Increasing reliance of U.S. colleges and universities on student tuition makes recruitment a high priority for geoscience departments. In 2017, $70 \%$ of geoscience graduates did not enter university declaring geology as a major, up by $10 \%$ since 2013 (Wilson, 2019). They discovered geology by taking an introductory geoscience course to fulfill general education or a previous major's requirement (Stokes et al., 2015). Thus, inspiring students to pursue a geoscience career through general education courses is a critical recruitment tool. However, what happens when these courses are taught online because of a pandemic, budget cuts, or to accommodate students' need for flexibility? It is not easy to be inspired through a computer screen.

This paper aims to describe two innovative pathways to recruit new undergraduate and graduate students at a large public research institution where, rather than focusing recruitment efforts on incoming students, a program recruits students who are already on campus and majoring in high-enrollment programs by offering them a path to earn a geology degree as a secondary major.

\section{GRADUATION RATES AND FUTURE EMPLOYMENT TRENDS}

The American Geosciences Institute (AGI; Gonzales and Keane, 2020) projects growth of $>20,000$ geoscience jobs by 2029 , a $4.9 \%$ increase from 2019 , higher than the projected growth in the U.S. workforce of $3.7 \%$. By comparing the number of projected retirements and geoscience graduates, the expected shortfall is $\sim 130,000$ fulltime geoscientists. While some of these positions will be covered by increased efficiency and use of technology, the expectation is that the demand will exceed the number of graduates and that programs will need an intentional focus on attracting and training new students.
AGI data (Wilson, 2019) show steady growth in geoscience undergraduates at four-year institutions since 2009 and a slight rise in degrees awarded since 2013 that do not match recent concerns expressed by departments about decreasing undergraduate enrollments. Data from the Integrated Postsecondary Education Data System (IPEDS, 2021) show that, of 288 geology programs at U.S. doctoral-granting institutions, $128(44 \%)$ saw a decline in graduates from 2013 to 2019. Almost 40\% of these programs (112) had fewer than 10 graduates in 2019, and 20 had none. Only 56 had $\geq 25$ graduates. In the same period, the number of graduates in half of the 123 geology/earth-science programs at B.S.and M.S.-granting institutions increased or stayed the same.

\section{GEOLOGY AS SECONDARY UNDERGRADUATE MAJOR}

Most science, technology, engineering, and math (STEM) majors must complete one year of calculus and physics and one or two semesters (one to three quarters) of chemistry. Some degrees require additional math and physics courses, often enough to earn a minor. On the other hand, a double major adds several more courses and typically at least one year to the undergraduate degree, delaying students' entrance into the workforce and adding to their financial burden.

The situation at Iowa State University (ISU) is typical of many geoscience departments: More than half of the geology graduates enrolled between 2004 and 2013 had entered the university either as undeclared $(13 \%)$, engineering $(11 \%)$, meteorology $(4 \%)$, physics (4\%), or one of 19 other majors. They had discovered geology through an introductory course or the learning community (Cervato and Flory, 2015). Most enroll in the B.S. geology, with smaller numbers pursuing B.S./B.A. earth-science degrees. This paper focuses on the B.S. geology program, the most popular undergraduate geoscience degree in the U.S. (66.6\% of 2013-2017 graduates; Wilson, 2019).

The author has actively pursued STEM recruitment for more than a decade in collaboration with colleagues in other departments. These efforts include the physics+ program, an alternative path to a double major inspired by the Engineering Physics program at the University of Illinois at Urbana-Champaign. It consists of core physics courses to which additional physics courses can be added to create a traditional physics degree or courses in other majors that could replace equivalent physics courses. These degrees, e.g., B.S. physics with aerospace engineering emphasis, are considered double majors and intended for students who do not plan to pursue graduate studies in physics.

Unlike physics, only a few programs require a geology course. Thus, the author adopted a different approach to creating "geology+" programs and focused instead on identifying majors with an affinity for geology to provide pathways to geology for students in select majors. Similar paths were created for meteorology and aerospace and electrical engineering.

The first step of the year-long process was producing a geology "core" program. By comparing our B.S. geology curriculum with Drummond and Markin's (2008) analysis of nearly 300 B.S. geology degrees offered in the U.S., as well as the degree requirements at ten peer land-grant institutions, we identified 31 credits of core courses and labs (introductory physical and historical geology, mineralogy and optical mineralogy, petrology, sedimentology and stratigraphy, structural geology, and field camp) that include courses required by more than $60 \%$ of the programs analyzed by Drummond and Markin (2008), with the addition of optical mineralogy. Although the department agreed that these courses represent the foundation of geology, we also agreed that this reduced

GSA Today, v. 31, https://doi.org/10.1130/GSATG503GW.1. CC-BY-NC. 
curriculum is only acceptable for students also majoring in another program.

Next, we identified programs with similar math, physics, and chemistry requirements and professional similarities with the broad field of geology (materials science and engineering, civil engineering, and environmental science) or that complement it (biology and meteorology). Collectively, there are close to 2,000 undergraduates majoring in these programs at ISU. Just $1 \%-2 \%$ of these students pursuing a geology + degree would add a significant number of majors to the program.

Working with advisors and departmental and college curriculum committees, we put together and received approval for four-year plans for each of these programs, fulfilling all primary major requirements while adding the geology core courses as a secondary major. Since this is a different approach than the one developed in physics, and there are no other examples at ISU, the validation process for these double majors required approval in each college involved.

Some characteristics that make this pathway to geology attractive to students include the ability to graduate in four years with two majors, the added professional benefit of a geology degree in a competitive job market, and the opportunity to pursue a career or graduate degree in geology. It is not unusual for geology graduate programs to admit students with degrees in biology, chemistry, physics, civil engineering, or environmental science. Completing the core geology courses in addition to their primary major's requirements would make the transition into a geology graduate program relatively smooth. Also, the M.S. geology degree has historically been the preferred professional degree for private-sector jobs in geoscience (Wilson, 2019), whereas the Ph.D. is the graduate degree of choice for some programs like materials engineering.

\section{GROWING GRADUATE PROGRAM THROUGH CONCURRENT B.S./M.S. DEGREES}

Increasing numbers of students enter university with college credits earned in high school through dual enrollment programs, advanced placement courses, or credits transferred from two-year institutions. ISU offers 30 concurrent B.S./M.S. or B.S./MBA programs that allow students to earn a B.S. and M.S. or MBA in five years in engineering, agronomy, chemistry, and more.

The ability to earn concurrent B.S. and M.S. degrees within five years is motivated in part by the M.S. becoming the degree of choice in many disciplines, including the geosciences (e.g., in oil and gas, federal government) (Levine, 2011; Wilson, 2019). Taken sequentially, it takes on average $>6.5$ years to earn both degrees (Wilson, 2018). This extended time could discourage students interested in a STEM career from pursuing a degree in geosciences in favor of a degree in engineering, for example, where starting positions require only a B.S.

We developed B.S./M.S. and B.S./MBA geology programs aimed at students pursuing a career in industry or as consultants. To our knowledge, there are only three other B.S./M.S. geoscience programs in the U.S. (two at Penn State and one at the University of Texas at El Paso), and none that include the MBA. While the primary goal is career preparation, the B.S./M.S. program might be a potential mechanism to increase the number of students who pursue a Ph.D. in geosciences $(\sim 18 \%$ of B.S. graduates in 2017; Wilson, 2018).

Students apply to the graduate program in their junior year after identifying a graduate advisor and complete graduate courses in their fourth and fifth years. Using this as a recruiting tool for students transferring from two-year institutions that tend to have a higher percentage of underrepresented minorities would potentially provide an opportunity to increase a program's diversity (Wilson, 2018). As for the traditional M.S. geology degree, there is a thesis and a rarely pursued non-thesis (creative component) option. Students are eligible for graduate teaching and research assistantships in their fourth and fifth years and reduced or free tuition as part of the graduate assistantship package.

\section{CONCLUSIONS}

We started accepting students into the geology+ program in fall 2019, and there are currently eight students from civil engineering, biology, meteorology, and environmental science who have declared geology as a secondary major. So far, there are a handful of students pursuing the B.S./M.S. option. However, we foresee this as an attractive recruiting tool and an opportunity to diversify the student body through partnerships with university programs to attract women and underrepresented minorities to STEM fields.

\section{ACKNOWLEDGMENTS}

I wish to thank Craig Ogilvie and Marzia Rosati for introducing me to the physics+ program and two anonymous reviewers for their helpful suggestions on the manuscript.

\section{REFERENCES CITED}

Cervato, C., and Flory, D., 2015, Earth, wind \& fire: A learning community approach to build ties between degree programs in a geoscience department: Journal of Geoscience Education, v. 63, p. 41-46, https://doi.org/10.5408/14-018.

Drummond, C., and Markin, J., 2008, An analysis of the bachelor of science in geology degree as offered in the United States: Journal of Geoscience Education, v. 56, no. 2, p. 113-119, https:// doi.org/10.5408/1089-9995-56.2.113.

Gonzales, L., and Keane, C., 2020, Geoscience Workforce Projections 2019-2029: https://www .americangeosciences.org/geoscience-currents/ geoscience-workforce-projections-2019-2029 (accessed 19 Feb. 2021).

IPEDS, 2021, Integrated Postsecondary Education Data Center of the National Center for Education Statistics: https://nces.ed.gov/ipeds/datacenter/ (accessed 22 Feb. 2021).

Levine, A.J., 2011, M.S. or Ph.D.: Which is right for me?: American Geophysical Union, $25 \mathrm{p}$.

Stokes, P.J., Levine, R., and Flessa, K.W., 2015, Choosing the geoscience major: Important factors, race/ethnicity, and gender: Journal of Geoscience Education, v. 63 , p. 250-263, https://doi .org/10.5408/14-038.1.

Wilson, C., 2018, Status of Recent Geoscience Graduates: American Geosciences Institute Report, https://www.americangeosciences.org/sites/ default/files/ExitSurvey_2017_Online_041018.pdf (accessed 19 Feb. 2021).

Wilson, C., 2019, Status of Geoscience Workforce: American Geosciences Institute Report, 163 p.

Manuscript Received 24 Feb. 2021

Revised MANusCRipt ReCEIVEd 6 Apr. 2021

ManusCript ACCEPTED 12 Apr. 2021 